\title{
Bulk Compositions and Zinc Contents of Micas from the Sterling Hill and Franklin Zn-Fe-Mn Deposits, New Jersey
}

Melinda B. Bahruth ${ }^{1}$, James D. Webster ${ }^{2}$, Earl R. Verbeek ${ }^{3}$

${ }^{1}$ Wichita State University, Kansas; ${ }^{2}$ American Museum of Natural History, NY; ${ }^{3}$ Franklin Mineral Museum, NJ

The Sterling Hill and Franklin Zn-Fe-Mn deposits near Ogdensburg, New Jersey, are home to more than 360 known mineral species, many of them rare or unknown elsewhere. Limited, prior research shows that many of the rock-forming minerals in and near the ore-bodies, particularly species of the pyroxene, amphibole, and of the proups, contain uncole, and mica groups, contain uncommonly high amounts of zinc. The Sterling Hill and Franklin micas have been. shown to contain above-average zinc contents (Frondel and Einaudi, 1968), and Franklin is the type locality of Hendricksite, a rare trioctahedral mica containing more than 19 wt\% ZnO. The goal in studying the zinc-rich micas from these deposits is to better constrain the roles of fluid or mineralogical controls in the formation, metamorphism and alteration of the deposits.

\section{Introduction}

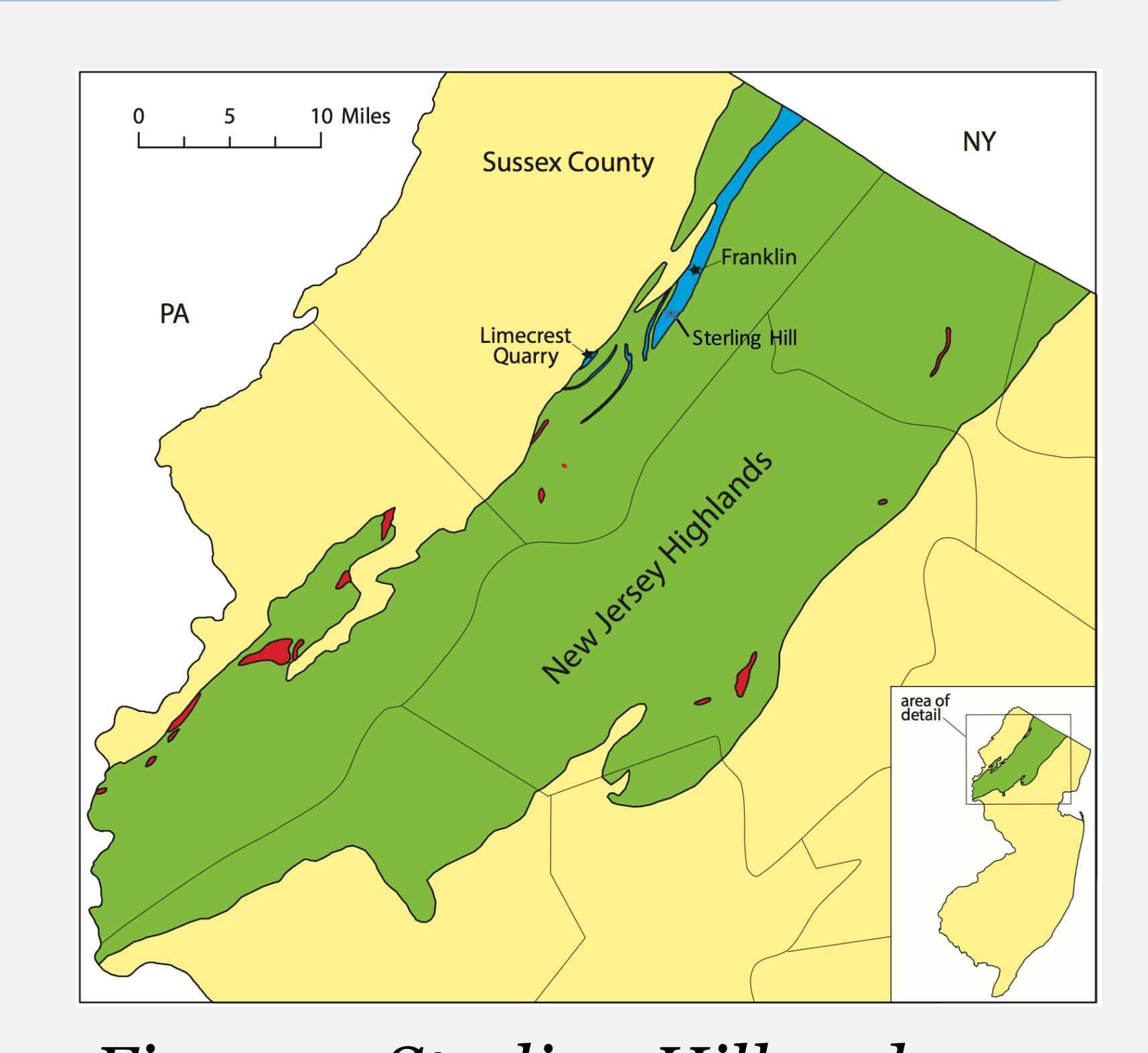

Figure 1. Sterling Hill and ranklin Deposits are within the ranklin Marble. Image: $N J$ Geological and Water Survey

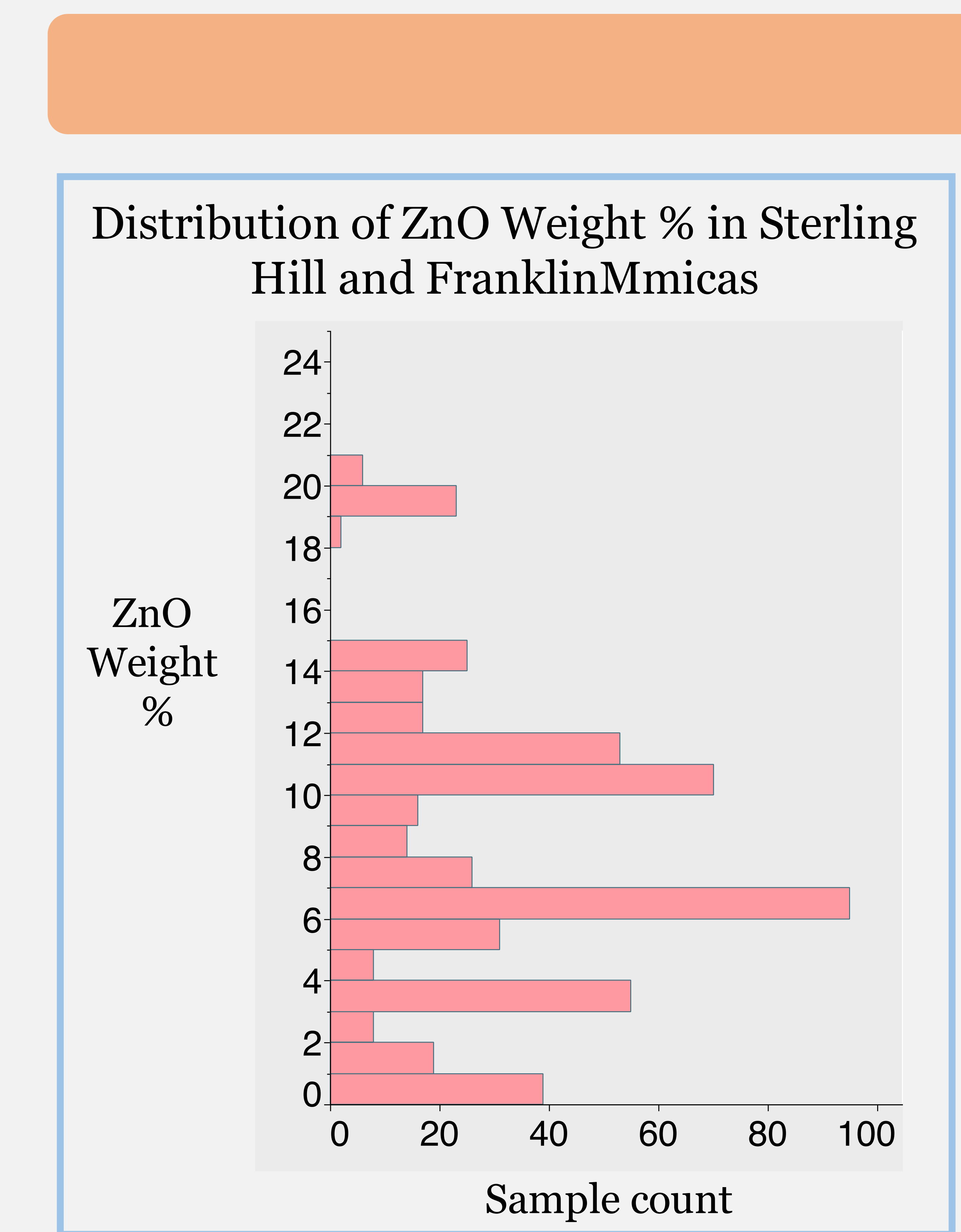

- Bulk compositional data were

Cation values were calculated based

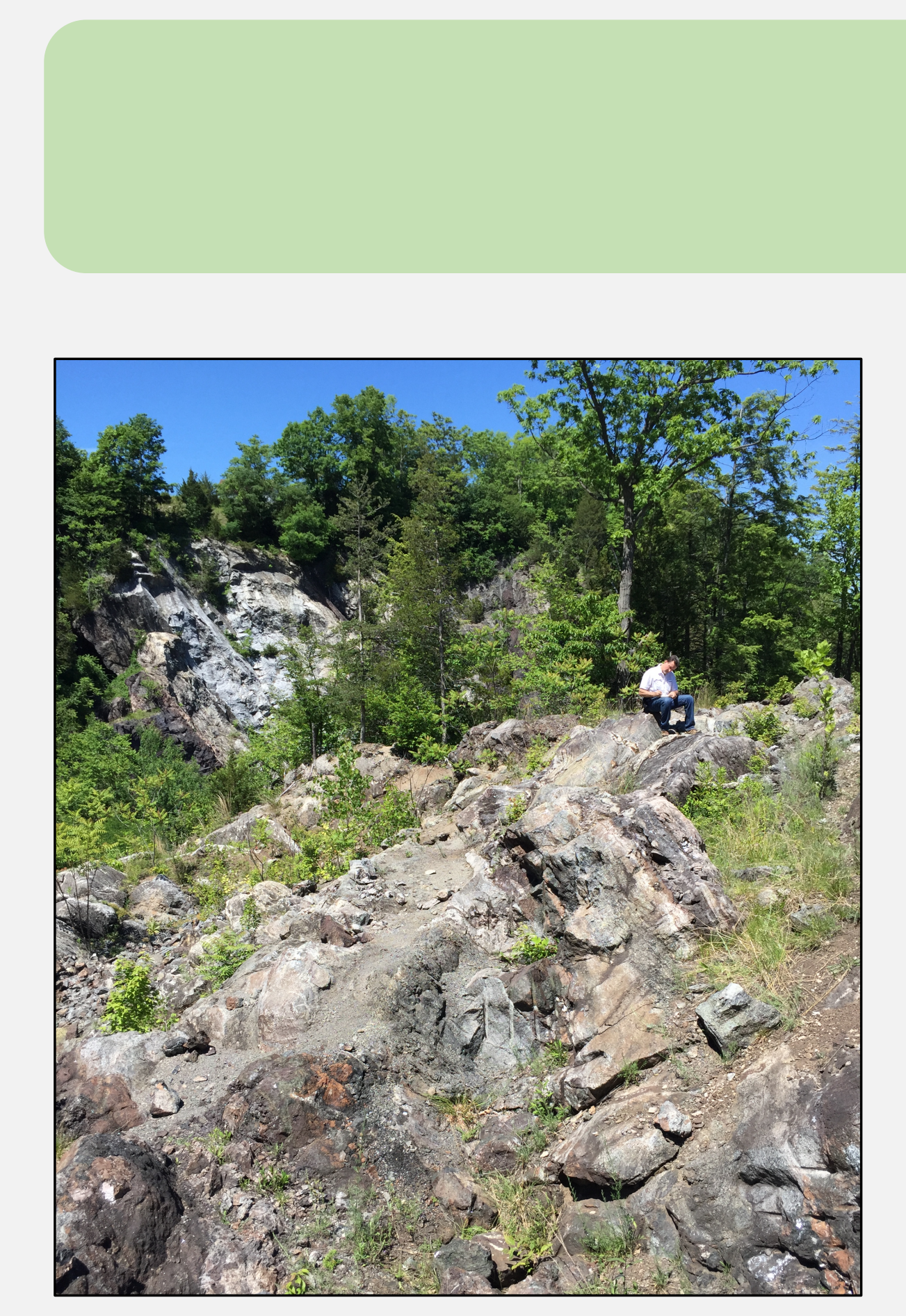

Figure 2. Sterling Hill collection site.
Methods

Collected mica-bearing samples from Sterling Hill and Franklin.

Used the scanning electron microscope to detect zoning and high zinc mineral phases.

acquired with electron microprobe.

on charge balance per site for the

expected mica formula.

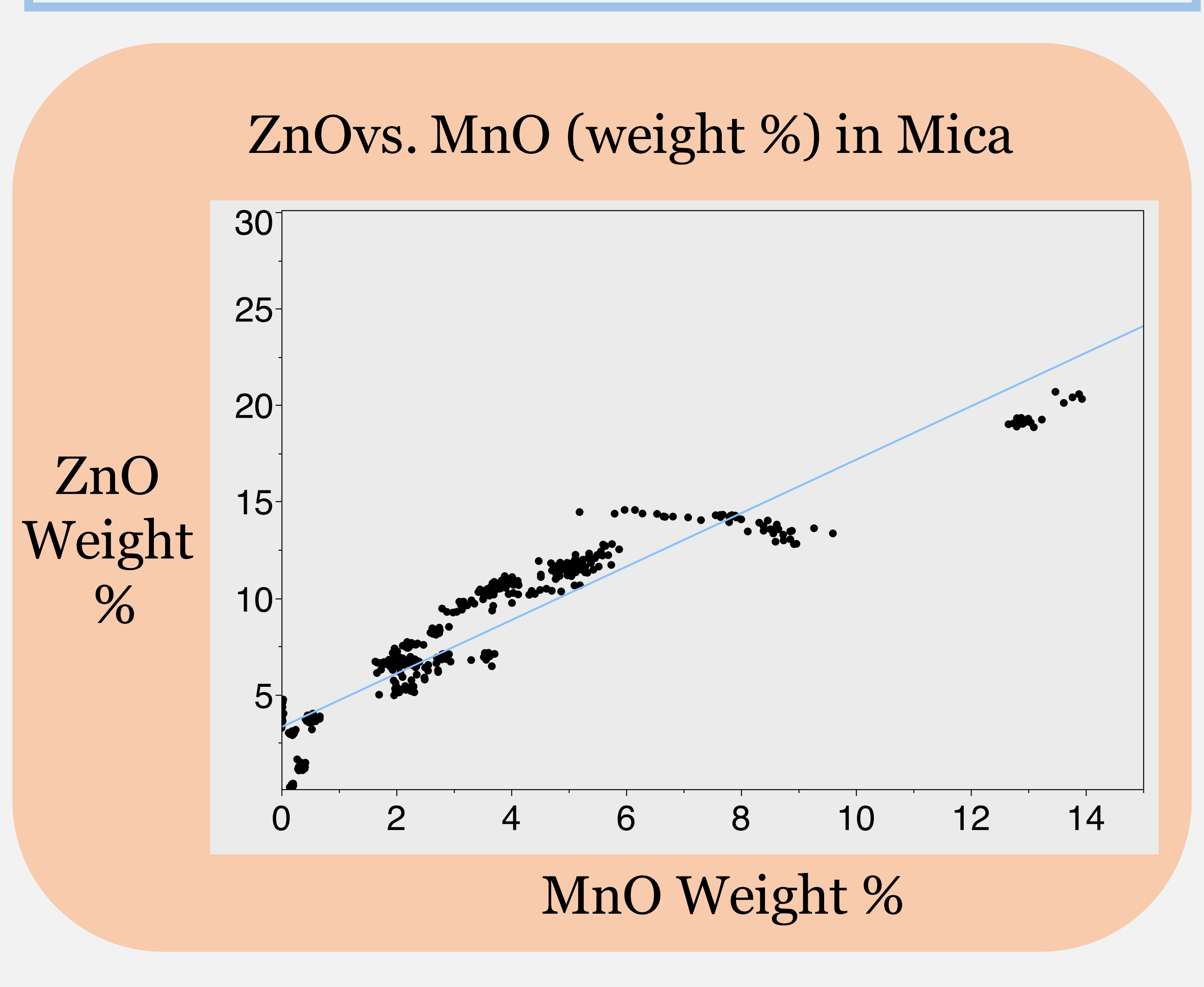

Literature Cited

Frondel, C. Einaudi, M. (1968) Zinc-rich micas from Sterling Hill, NJ. Amer. Mineral. 53, p. 1752

Tracy, R.J. (1991) Ba-rich micas from the Franklin Marble, Lime Crest and Sterling Hill, New Jersey. Amer. Mineral. 76, 1683-1693.

Volkert, Richard A. (2013) The Franklin Marble: One of New Jersey's Most Famous Geologic Formations, New Jersey

Geological and Water Survey, Information Circular.

\section{Results}

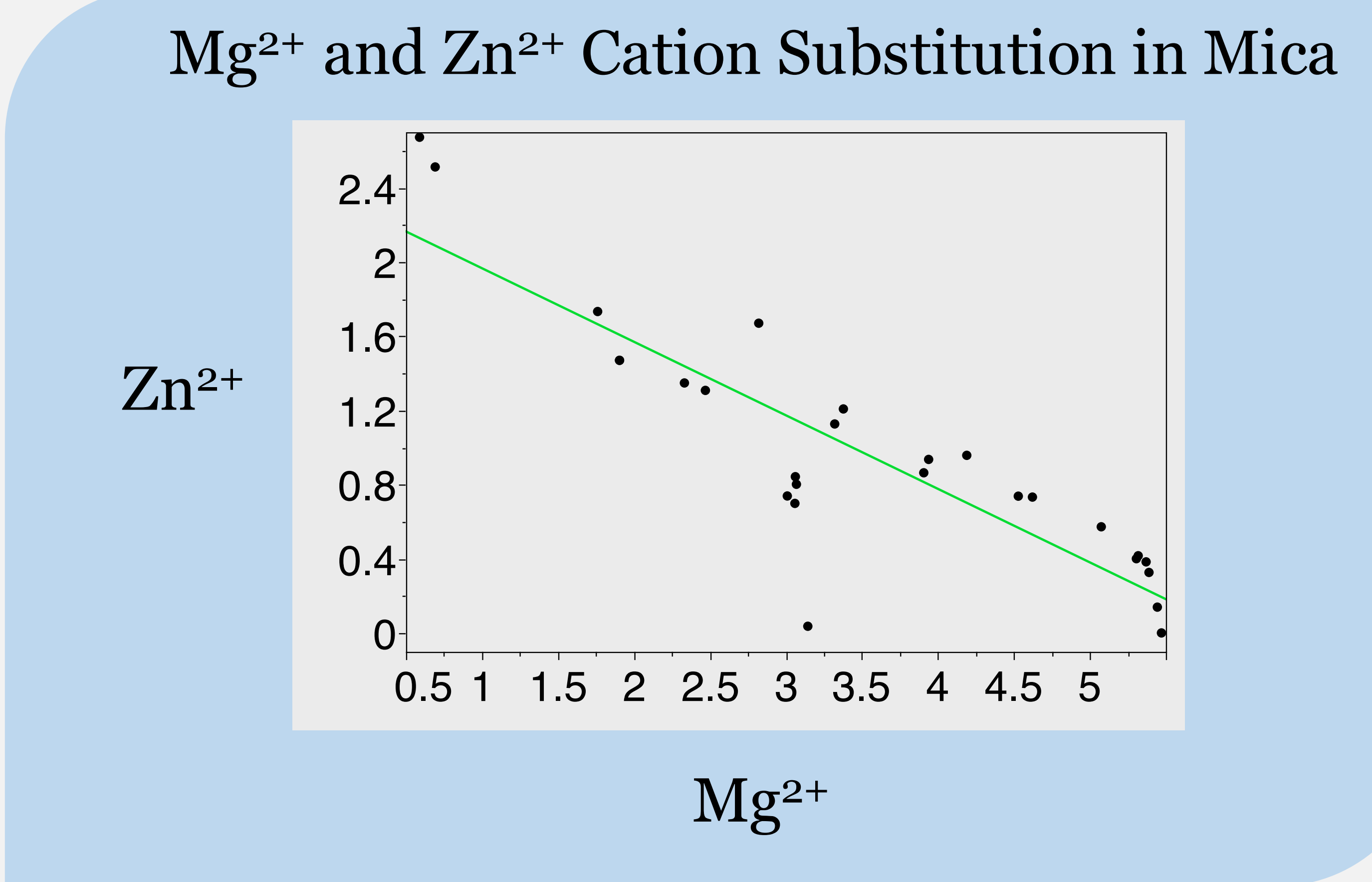

Standard Mica Formula $\mathrm{X}_{2} \mathbf{Y}_{4-6} \mathrm{Z}_{8} \mathrm{O}_{20}(\mathrm{OH}, \mathrm{F}, \mathrm{Cl})_{4}$

$\mathbf{Z}=$ Tetrahedral site $\left(\mathrm{Si}, \mathrm{Al}, \mathrm{Ti}, \mathrm{Fe}^{3+}\right)$

$\mathbf{Y}=$ Octahedral site (Al, Mg, Mn, Ti, Zn, $\mathrm{Fe}^{2+}$ )

$\mathbf{X}=$ Interlayer Cation Site $(\mathrm{K}, \mathrm{Na}, \mathrm{Ca}, \mathrm{Ba})$

Complex Tschermak's Substitution in Micas of Sterling Hill and Franklin, NJ

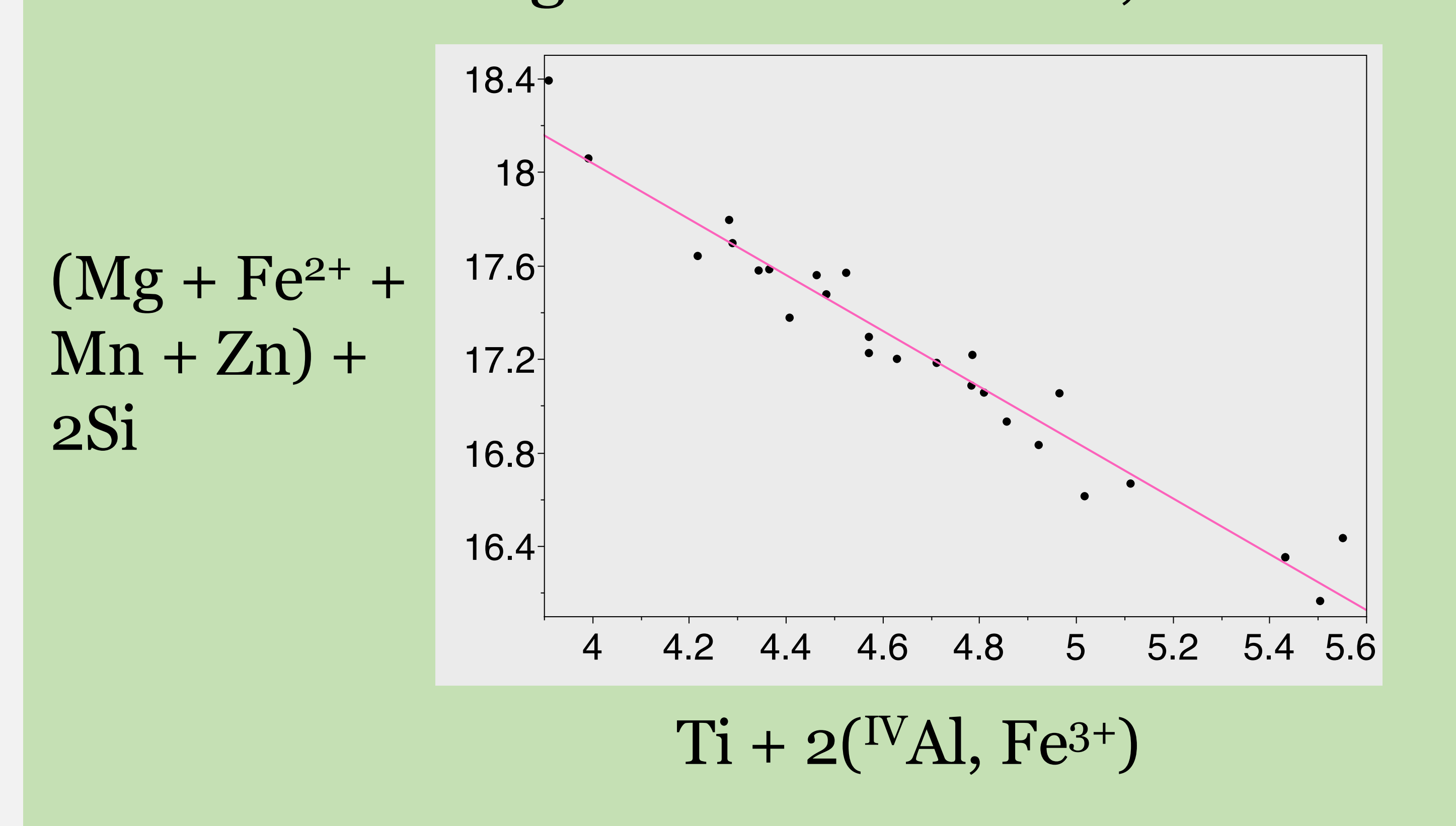

\section{Acknowledgements}

Thank you to the National Science Foundation for funding this research. Thank you Hans-Juerger Foerster, Beth Goldoff, Georg Harlow, Adrian Fiege, Saebyul Choe, Nick Tailby, Morgan Hill, Henry Towbin, Nanette Nicholson, Jamie Newman, Maria Rios, Charles Liu, Sam Alpert for the knowledge and help you provided.
There are no micas plotting between 15-18 weight $\%$

* No obvious zoning was found in the micas.

The majority of the micas analyzed are in the biotite solid solution series, trending toward phlogopite.

- Two samples appear to be hendricksite, containing more than 19 weight $\% \mathrm{ZnO}$.

- Complex Tchermak's substitution is observed in micas from both deposits.

* Weight \% ZnO correlates negatively with $\mathrm{MnO}, \mathrm{F}$, $\mathrm{SiO} 2, \mathrm{MgO}$ and positively with $\mathrm{FeO}$ in mica.

- BaO contents of many micas are nearly 9 wt\%, consistent with Ba-rich micas of Franklin analyzed previously by Tracy (1991).

\section{Conclusions}

The compositional data collected from the micas of Sterling Hill and Franklin are of high interest mineralogically and may have further applications in understanding the origin, metamorphism and alteration of the ore bodies. We interpret the lack of micas containing between $15-18$ weight \% $\mathrm{ZnO}$ to be a potential indicator of the universal behavior of micas when up-taking zinc, as there is no other literature describing micas in this range. If micas truly do not take up $15^{-18}$ weight $\% \mathrm{ZnO}$, then this eliminates the possibility of total solid solution from the low-Zn biotite system to the high$\mathrm{Zn}$ hendricksite. Biotite micas and the hendricksite from both deposits follow the same pattern of Tschermak's substitution, wherein there is replacement of $\mathrm{Ti}^{4+}$ with either $\mathrm{Mg}^{2+}, \mathrm{Fe}^{2+}$, $\mathrm{Mn}^{2+}$ or $\mathrm{Zn}^{2+}$ in the octahedral site, while simultaneously there is replacement of either $2 \mathrm{Al}^{++}$or $\mathrm{Fe}^{3+}$ with $2 \mathrm{Si}^{4+}$ in the tetrahedral site. Future work will examine other high-Zn phases from the deposits and their relationship to the Zn-rich

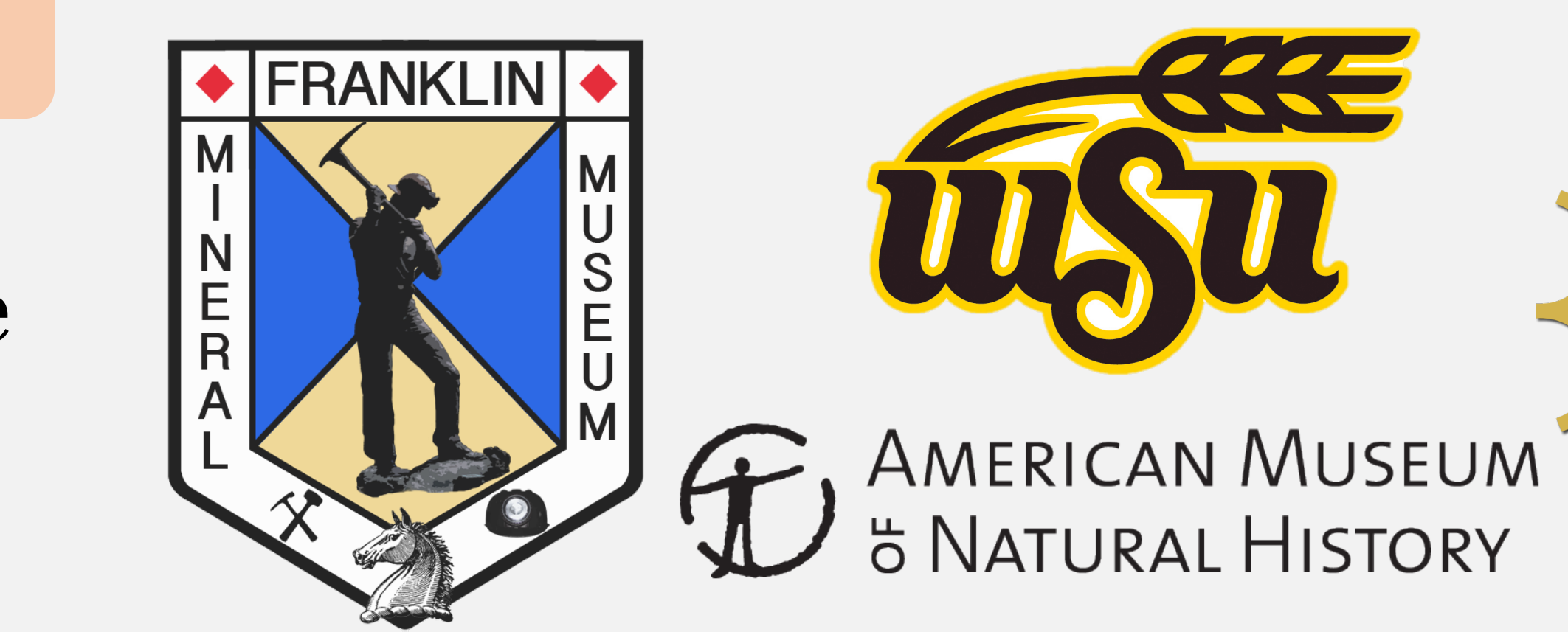

